\title{
Luminescence, Rock Surfaces
}

\author{
Reza Sohbati Ph.D. . a $^{*}, \mathrm{l}$ \\ ${ }^{a}$ Department of Geoscience, Aarhus University, Building 201, DTU Risø Campus, DK-4000, Roskilde, Denmark \\ ${ }^{\mathrm{b}}$ Center for Nuclear Technologies, Technical University of Denmark, Building 201, DTU Risø Campus, DK-4000, \\ Roskilde, Denmark
}

\section{Definition}

Luminescence is the light emitted following the release of stored energy (in the form of trapped charge) accumulated in crystalline materials; this energy accumulates in natural minerals such as quartz and feldspar through the absorption of ionizing radiation, either cosmic rays or resulting from the decay of naturally occurring radionuclides. This trapped charge can be released or reset by heat or light; if reset by heat, the light emitted from the mineral is called thermoluminescence (TL), and if released by photon stimulation, it is called optically stimulated luminescence (OSL). Thus, luminescence dating provides an estimate of the time elapsed since the mineral grains were last heated or exposed to daylight (Aitken 1998).

\section{Introduction}

In geology and archaeology, there are many examples of rock surfaces, rock art, and stone structures of unknown age. In archaeology, megaliths, buildings, chambered burial mounds, field walls, and cairns are very important to understanding the way in which people have used the landscape (Liritzis et al. 2013). In geology, there are examples of ice-scoured bedrock, ice-transported rocks (erratics), and cobble fans from extreme fluvial events whose ages are essential for understanding the evolution of the driving climate-related phenomena.

Luminescence dating is a well-established method of absolute chronology that has been successfully applied to a wide range of fine-grained sediments to provide depositional ages from a few years (Madsen and Murray 2009) to several tens of thousands (e.g., Murray and Olley 2002; Duller 2004) and even several hundred thousand years (e.g., Watanuki et al. 2005; Wang et al. 2006; Porat et al. 2010; Buylaert et al. 2012). The luminescence age of a sample is calculated by dividing the amount of ionizing radiation the sample absorbed during burial (measured as the equivalent dose, $\mathrm{D}_{\mathrm{e}}$ ) by the rate of energy absorption (the dose rate) from the environment. The single-aliquot regenerative dose $(\mathrm{SAR})$ procedure is the standard approach to $\mathrm{D}_{\mathrm{e}}$ determination in quartz and feldspar (Murray and Wintle 2000; Wallinga et al. 2000; Auclair et al. 2003; Buylaert et al. 2012). Dose rate calculations are dependent on the spatial distribution of energy deposition rates by the various radiations $(\alpha, \beta, \gamma)$. Aitken (1985) outlines an approach to such calculations near interfaces (including buried rock surfaces), although later authors suggest that the details of this approach may require modification (Yang et al. 1998).

\section{Development of the Luminescence Dating of Rock Surfaces}

Early attempts to date buried rock surfaces used the TL signal from calcitic rocks; this approach was based on the idea that the signal was lost as a result of exposure to daylight before burial. Liritzis (1994) proposed the use of TL to date the construction of a megalithic limestone building.

${ }^{1}$ Email: resih@dtu.dk. 
Similarly, attempts were made to determine the ages of the Apollo Temple at Delphi (Liritzis et al. 1997) and of limestone pyramids in Greece (Theocaris et al. 1997). However, even after long exposures to sunlight, a significant residual TL signal remains (Liritzis and Galloway 1999); this significantly limits the youngest ages that can be determined using this method. To circumvent this problem, later studies investigated the potential of the OSL signal; it was known from the earliest days of sediment dating that this signal bleaches much more quickly and to a much lower level than TL signals (e.g., Huntley et al. 1985). Early attempts were reported by Huntley and Richards (1997) in which they tried to determine the burial age of quartzite pebbles using OSL. They showed that there can be sufficient light penetration for OSL dating to be used on a surface layer. However, for most of their samples, the quartz gave so little luminescence in response to optical stimulation that their attempts to obtain reliable equivalent doses did not succeed. Trying to develop a non-destructive surface dating method, Habermann et al. (2000) built a new measurement instrument with which they measured an infrared stimulated luminescence (IRSL) signal from the surface of granitic rock; they related this to the dose accumulated since the last exposure to light. They also showed that almost complete bleaching to a depth of at least $2 \mathrm{~mm}$ can result from only a few minutes of exposure to sunlight. Morgenstein et al. (2003) used IRSL to date the fine-grained feldspar fraction scraped off the uppermost part from the bleached surface of lithic artifacts. However, the ages they obtained were not in agreement with the available age controls. They attributed this to anomalous fading (unexpected loss of signal due to quantum tunneling phenomenon in feldspars) and partial bleaching of feldspar grains. Following the idea proposed by Habermann et al. (2000), Greilich et al. (2005) used a high-spatial-resolution detection technique (HR-OSL) for OSL based on a CCD camera system to date a stone wall of the medieval castle of Lindenfels in southwestern Germany and the pre-Columbian Nasca lines (geoglyphs) around Palpa in southern Peru. Using the infrared stimulated yellow emission from their samples, they obtained some ages in agreement with archaeological age control. However, they did not take into account anomalous fading which is known to be very common (if not universal; Huntley and Lian 2006) in the IRSL signals from feldspars. Vafiadou et al. (2007) obtained useful signals from granitic rocks using the blue stimulated ultraviolet (UV) signal originating from whole rock slices and reported complete daylight bleaching up to a depth of $5 \mathrm{~mm}$ after 14 days of exposure to sunlight for all of their samples. More studies on the application of TL and OSL signals to rock surfaces from archaeological sites have been carried out by Liritzis et al. (2008, 2010a, b); however, none of these is supported by independent age control. Liritzis (2011) reviews most of these studies of luminescence rock surface dating. Simms et al. (2011) tried to reconstruct sea levels in Antarctica by measuring OSL from quartz grains obtained from the underside of cobbles within raised beaches and boulder pavements. The ages they obtained were internally consistent and agreed with radiocarbon ages. However, their quartz grains were contaminated with feldspar and they had to take into account both fading and internal dose rate (Simms et al. 2011).

In a very different approach, Polikreti et al. (2003, 2007) suggested the possibility of using luminescence to estimate the length of time a rock surface was exposed to daylight; this would give similar information to that obtained from cosmogenic nuclide $(\mathrm{CN})$ dating. While looking for a method to determine the authenticity of marble artifacts of disputed age, they investigated the bleaching of the TL signal with depth in several samples and developed a model to describe the dependence of TL intensity on exposure time and depth; however, they were unable to estimate values for parameters in their model and so could not quantify the exposure time. Sohbati et al. (2011) studied the depth dependence of the bleaching of the IRSL signal from granitic rocks. Using some simplifying assumptions, they presented a model of this dependence and showed it to be a good descriptor of the remaining luminescence in their naturally exposed 
samples. According to their model, the longer the exposure time, the further into a rock surface the luminescence is reset. However, they were unable to determine realistic estimates for some of the parameters in the model from first principles, and they did not have any sample of known exposure history with which to calibrate their model. Shortly afterward, Laskaris and Liritzis (2011) proposed a mathematical function to describe the attenuation of daylight into rock surfaces. However, their suggested approximation depends on the assumption that the residual luminescence as a function of depth into rock surfaces has a log-normal distribution, an assumption for which there does not appear to be any physical basis.

Sohbati et al. (2012a) overcame the problem of parameter estimation by using a known-age road-cut sample for calibration. They then used the resulting parameter values to estimate the exposure times of samples of unknown age. One of their samples was a buried rock surface on which pigment from an extant rock painting was found. They were able to model the distortion in the OSL-depth resetting profile resulting from subsequent burial. This allowed them to determine a pre-burial exposure period age for their sample. This study was the first to report credible exposure ages obtained using OSL surface exposure dating. In a related study, Chapot et al. (2012) derived a burial age for the same sample by dating the outer 1-mm surface of the buried boulder. This age was supported by the OSL age of single grains of sediment buried under the boulder and by the ${ }^{14} \mathrm{C}$ age of a leaf buried between the boulder and the underlying sediment. Together, the two studies constrained the age of the Great Gallery, an archaeologically significant Barrier Canyon Style (BCS) rock art in Canyonlands National Park, Utah, USA.

As a part of an investigation into the burial age of an alluvial cobble pavement at an archaeological site in Portugal, Sohbati et al. (2012b) further developed their model to include the environmental dose rate. The new model successfully described the variation of dose with depth and time into a quartzite cobble and allowed them to identify and quantify four events (two light exposures of different durations and two sequential burial periods) in the dose record contained within a single clast. Sohbati et al. (2012b) showed that, for the first time, prolonged periods of exposure can leave a distinct bleaching record in the luminescence/dose profile with depth into a rock surface and, thus, that it may be possible to identify and date multiple deposition events in one sample.

In their model, Sohbati et al. (2012b) assume that, during daylight exposure, the rate of trapped charge accumulation from natural ionizing radiation was negligible compared to the rate of detrapping due to daylight bleaching. However, they discuss that this assumption is only valid for dating those terrestrial objects which have a short exposure history and a low environmental dose rate. In considering the potential application of their technique in dating non-terrestrial surfaces, where environmental dose rates can be orders of magnitude greater than that on Earth, Sohbati et al. (2012c) further developed the OSL surface exposure dating model by including the simultaneous effect of daylight bleaching and environmental dose rate. This now represents the most complete model of OSL resetting with depth so far presented and has the potential to date non-terrestrial geomorphological features such as fault movements, rockfalls, landslides, volcanic eruptions, and crater impacts, with an upper limit to the method of between 10 and $100 \mathrm{ka}$ on, for example, the Martian surface.

\section{Discussion}

Despite the recent progress with luminescence dating of rock surfaces, especially the potential application of this method in surface exposure dating, a widely applicable method has not yet been agreed upon. In sample preparation, for example, some favor working with grains extracted from rock surfaces (e.g., Simms et al. 2011; Chapot et al. 2012; Sohbati et al. 2012a), while 
others prefer to measure 1-1.5-mm-thick intact slices cut from the cores drilled into the rock surfaces (e.g., Greilich et al. 2005; Vafiadou et al. 2007; Sohbati et al. 2012b). In part, this is imposed by the nature of the samples and the fact that solid slices cannot be recovered from friable rock types (e.g., Chapot et al. 2012; Sohbati et al. 2012a). However, the significance of the issue goes beyond the physical properties of rocks and sampling methods and appears to be of dosimetric importance; Sohbati et al. $(2011,2012 b)$ report a difference between doses measured from grains and slices recovered from the same surface for two different rock types. Unfortunately, their investigation into the source of this discrepancy did not result in a conclusive answer.

The above problem also relates to the choice of a luminescence mineral. Although quartz is often the preferred dosimeter in sediment dating, it is often not sufficiently sensitive when extracted from solid rocks (e.g., Huntley and Richards 1997; Tsukamoto et al. 2011; Sohbati et al. 2011). The intensity of signals from feldspars tends to be much less dependent on geological origin and erosion history, but the dosimetry of K-rich feldspar grains extracted from rocks is complicated because the internal dose rate is very dependent on the original feldspar grain size. The in situ grain size information is lost during the crushing process used to separate the grains for measurement. There have been attempts to circumvent this problem by using a non-destructive technique based on high-resolution spatially resolved luminescence detection from whole rock slices at a microscale level (e.g., Habermann et al. 2000; Greilich et al. 2002, 2005). However, dose measurement at the microscale level requires dose rate determination on the same scale for age derivation (Guérin et al. 2013); this is unlikely ever to be routine because it requires complex microdosimetry modeling in rock surfaces to include beta dose rate heterogeneity (see Nathan et al. 2003). This problem does not apply to Na-rich feldspar to the same degree because of the absence of internal radioactivity. Sohbati et al. (2013) investigated the potential application of Na-rich feldspar as a potential luminescence dosimeter for the IRSL dating of rock surfaces. The elevated-temperature IRSL signal at $290^{\circ} \mathrm{C}$ that they measured after an IR bleach at $50{ }^{\circ} \mathrm{C}$ (pIRIR ${ }_{290}$ signal) in the yellow emission seemed to be the most reliable signal for dating rock surfaces in their study; however, they speculated that higher preheat and stimulation temperatures (i.e., $>320^{\circ} \mathrm{C}$ and $290{ }^{\circ} \mathrm{C}$ for preheat and stimulation temperatures, respectively) may result in an even more stable yellow emission signal from Na-rich feldspar.

\section{Conclusions}

Direct luminescence dating of rock surfaces is a viable method for dating various geological and archaeological phenomena, including some that cannot be dated using sediments. Depending on the rock type and the sensitivity of quartz extracted from rock surfaces, quartz OSL and Na-rich feldspar pIRIR yellow signals can be used as reliable and dosimetrically tractable signals in the OSL and IRSL dating of rock surfaces. Unlike most sediments, rock surfaces can be exposed for prolonged periods; such long exposure periods leave a distinct bleaching record in the luminescence/dose profile with depth into a cobble. Thus, the degree of bleaching of a rock surface is recorded within that surface, and in favorable circumstances it is possible to identify and date multiple burial events in one sample.

The new technique of OSL surface exposure dating has considerable potential in the dating of many archaeological and geological features, such as the time of construction of megaliths, agricultural land clearance and enclosure, glacial advances and retreats, phases of erosion, and other geological processes and hazards such as mass-wasting and fault scarp movement. The method is also ideally suited to the problem of in situ measurement of the age of young $\left(<10^{5}\right.$ years $)$ exposed surfaces on non-terrestrial bodies. 


\section{Cross-References}

Luminescence Dating

Luminescence Dating, Dose Rate

Luminescence Dating, History

Luminescence, Flints and Stones

Luminescence, Martian Sediments

Luminescence Dating, Meteorites

Luminescence, Volcanic Rocks

\section{Bibliography}

Aitken, M. J., 1985. Thermoluminescence Dating. London: Academic Press.

Aitken, M. J., 1998. An Introduction to Optical Dating. Oxford: Oxford University Press.

Auclair, M., Lamothe, M., and Huot, S., 2003. Measurement of anomalous fading for feldspar IRSL using SAR. Radiation Measurements, 37, 487-492.

Buylaert, J.-P., Jain, M., Murray, A. S., Thomsen, K. J., Thiel, C., and Sohbati, R., 2012. A robust feldspar luminescence dating method for Middle and Late Pleistocene sediments. Boreas, 41, 435-451.

Chapot, M. S., Sohbati, R., Murray, A. S., Pederson, J. L., and Rittenour, T. M., 2012. Quaternary Geochronology Constraining the age of rock art by dating a rockfall event using sediment and rock-surface luminescence dating techniques. Quaternary Geochronology, 13, $18-25$.

Duller, G. A. T., 2004. Luminescence dating of quaternary sediments: recent advances. Journal of Quaternary Science, 19, 183-192.

Greilich, S., Glasmacher, U. A., and Wagner, G. A., 2002. Spatially resolved detection of luminescence: a unique tool for archaeochronometry. Die Naturwissenschaften, 89, 371-375.

Greilich, S., Glasmacher, U. A., and Wagner, G. A., 2005. Optical dating of granitic stone surfaces. Archaeometry, 47, 645-665.

Guérin, G., Murray, A. S., Jain, M., Thomsen, K. J., and Mercier, N., 2013. How confident are we in the chronology of the transition between Howieson's Poort and Still Bay? Journal of Human Evolution, 64, 314-317.

Habermann, J., Schilles, T., Kalchgruber, R., and Wagner, G. A., 2000. Steps towards surface dating using luminescence. Radiation Measurements, 32, 847-851.

Huntley, D. J., and Lian, O. B., 2006. Some observations on tunnelling of trapped electrons in feldspars and their implications for optical dating. Quaternary Science Reviews, 25, 2503-2512.

Huntley, D. J., and Richards, M., 1997. The age of the Diring Quriakh archaeological site. Ancient TL, 15, 48-51.

Huntley, D. J., Godfrey-Smith, D. I., and Thewalt, M. L. W., 1985. Optical dating of sediments. Nature, 313, 105-108.

Laskaris, N., and Liritzis, I., 2011. A new mathematical approximation of sunlight attenuation in rocks for surface luminescence dating. Journal of Luminescence, 131, 1874-1884.

Liritzis, I., 1994. A new dating method by thermoluminescence of carved megalithic stone building. Comptes Rendus de l'Académie des Sciences-Série II, 319, 603-610.

Liritzis, I., 2010. Strofilas (Andros Island, Greece): new evidence for the cycladic final neolithic 
period through novel dating methods using luminescence and obsidian hydration. Journal of Archaeological Science, 37, 1367-1377.

Liritzis, I., 2011. Surface dating by luminescence: an overview. Geochronometria, 38, 292-302.

Liritzis, I., and Galloway, R. B., 1999. Dating implications from solar bleaching of thermoluminescence of ancient marble. Journal of Radioanalytic and Nuclear Chemistry, 241, 361-368.

Liritzis, I., Guibert, P., Foti, F., and Schvoerer, M., 1997. The temple of Apollo (Delphi) strengthens novel thermoluminescence dating method. Geoarchaeology, 12, 479-496.

Liritzis, I., Sideris, C., Vafiadou, A., and Mitsis, J., 2007. Mineralogical, petrological and radioactivity aspects of some building material from Egyption Old Kingdom monuments. Journal of Cultural Heritage, 9, 1-13.

Liritzis, I., Kitis, G., Galloway, R. B., Vafiadou, A., Tsirliganis, N. C., and Polymeris, G., 2008. Probing luminescence dating of archaeologically significant carved rock types. Mediterranean Archaeology and Archaeometry, 8, 61-79.

Liritzis, I., Zacharias, N., and Polymeris, G., 2010. Surface luminescence dating of 'Dragon Houses' and Armena Gate at Styra (Euboea, Greece). Mediterranean Archaeology and Archaeometry, 10, 65-81.

Liritzis, I., Singhvi, A. K, Feathers, J. K., Wagner, G. A., Kadereit, A., Zacharias, N., and Li, S.-H., 2013. Luminescence Dating in Archaeology, Anthropology, and Geoarchaeology: An Overview. Springer Briefs in Earth System Sciences.

Madsen, A. T., and Murray, A. S., 2009. Optically stimulated dating of young sediments: a review. Geomorphology, 109, 3-16.

Morgenstein, M. E., Luo, S., Ku, T. L., and Feathers, J., 2003. Uranium-series and luminescence dating of volcanic lithic artefacts. Archaeometry, 45, 503-518.

Murray, A. S., and Olley, J. M., 2002. Precision and accuracy in the optically stimulated luminescence dating of sedimentary quartz: a status review. Geochronometria, 21, 1-16.

Murray, A. S., and Wintle, A. G., 2000. Luminescence dating of quartz using an improved single-aliquot regenerative-dose protocol. Radiation Measurements, 32, 57-73.

Nathan, R., Thomas, P. J., Jain, M., Murray, A. S., and Rhodes, E. J., 2003. Environmental dose rate heterogeneity of beta radiation and its implications for luminescence dating: Monte Carlo modelling and experimental validation. Radiation Measurements, 37, 305-313.

Polikreti, K., Michael, C. T., and Maniatis, Y., 2003. Thermoluminescence characteristics of marble and dating of freshly excavated marble objects. Radiation Measurements, 37, 87-94.

Polikreti, K., 2007. Detection of ancient marble forgery: techniques and limitations. Archaeometry, 49, 603-619.

Porat, N., Chazan, M., Grün, R., Aubert, M., Eisenmann, V., and Horwitz, L. K., 2010. New radiometric ages for the Fauresmith industry from Kathu Pan, southern Africa: Implications for the Earlier to Middle Stone Age transition. Journal of Archaeological Science, 37, 269-283.

Simms, A. R., DeWitt, R., Kouremenos, P., and Drewry, A. 2011. A new approach to reconstructing sea levels in Antarctica using optically stimulated luminescence of cobble surfaces. Quaternary Geochronology, 6, 50-60.

Sohbati, R., Murray, A. S., Jain, M., Buylaert, J.-P., and Thomsen, K. J., 2011. Investigating the resetting of OSL signals in rock surfaces. Geochronometria, 38, 249-258.

Sohbati, R., Murray, A. S., Chapot, M. S., Jain, M., and Pederson, J., 2012a. Optically stimulated luminescence (OSL) as a chronometer for surface exposure dating. Journal of Geophysical Research, 117, B09202.

Sohbati, R., Murray, A. S., Buylaert, J.-P., Almeida, N. A. C., and Cunha, P. P., 2012b. Optically stimulated luminescence (OSL) dating of quartzite cobbles from the Tapada do Montinho archaeological site (east-central Portugal). Boreas, 41, 452-462. 
Sohbati, R., Jain, M., and Murray, A., 2012c. Surface exposure dating of non-terrestrial bodies using optically stimulated luminescence: a new method. Icarus, 221, 160-166.

Sohbati, R., Murray, A., Jain, M., Thomsen, K., Hong, S.-C., Yi, K., and Choi, J.-H., 2013. Na-rich feldspar as a luminescence dosimeter in infrared stimulated luminescence (IRSL) dating. Radiation Measurements, 51-52, 67-82.

Theocaris, P. S., Liritzis, I., and Galloway, R. B., 1997. Dating of two Hellinic Pyramids by a novel application of thermoluminescence. Journal of Archaeological Science, 24, 399-405.

Tsukamoto, S., Nagashima, K., Murray, A. S., and Tada, R., 2011. Variations in OSL components from quartz from Japan sea sediments and the possibility of reconstructing provenance. Quaternary International, 234, 182-189.

Vafiadou, A., Murray, A. S., and Liritzis, I., 2007. Optically stimulated luminescence (OSL) dating investigations of rock and underlying soil from three case studies. Journal of Archaeological Science, 34, 1659-1669.

Wallinga, J., Murray, A. S., and Wintle, A., 2000. The single aliquot regenerative-dose (SAR) protocol applied to coarse-grain feldspar. Radiation Measurements, 32, 529-533.

Wang, X. L., Wintle, A. G., and Lu, Y. C., 2006. Thermally transferred luminescence in fine-grained quartz from Chinese loess: basic observations. Radiation Measurements, 41, 649-658.

Watanuki, T., Murray, A. S., and Tsukamoto, S., 2005. Quartz and polymineral luminescence dating of Japanese loess over the last $0.6 \mathrm{Ma}$ : comparison with an independent chronology. Earth and Planetary Science Letters, 240, 774-789.

Yang, Q., Rink, W. J., and Brennan, B. J., 1998. Experimental determinations of beta attenuation in planar dose geometry and application to ESR dating of tooth enamel. Radiation

Measurements, 29, 663-671. 